\title{
A Mixture of Persistent Organic Pollutants and Perfluorooctanesulfonic Acid Induces Similar Behavioural Responses, but Different Gene Expression Profiles in Zebrafish Larvae
}

\author{
Abdolrahman Khezri ${ }^{1, *}$, Thomas W. K. Fraser ${ }^{2}$, Rasoul Nourizadeh-Lillabadi ${ }^{1}$, \\ Jorke H. Kamstra ${ }^{1}$, Vidar Berg ${ }^{3}$, Karin E. Zimmer ${ }^{1}$ and Erik Ropstad ${ }^{2}$ \\ 1 Department of Basic Sciences and Aquatic Medicine, Faculty of Veterinary Medicine, \\ Norwegian University of Life Sciences, P.O. Box 8146 Dep., 0033 Oslo, Norway; \\ rasoul.nourizadeh-lillabadi@nmbu.no (R.N.-L.); jorke.kamstra@nmbu.no (J.H.K.); \\ karin.zimmer@nmbu.no (K.E.Z.) \\ 2 Department of Production Animal Clinical Sciences, Faculty of Veterinary Medicine, \\ Norwegian University of Life Sciences, P.O. Box 8146 Dep., 0033 Oslo, Norway; \\ thomas.fraser@nmbu.no (T.W.K.F.); erik.ropstad@nmbu.no (E.R.) \\ 3 Department of Food Safety and Infection Biology, Faculty of Veterinary Medicine, \\ Norwegian University of Life Sciences, P.O. Box 8146 Dep., 0033 Oslo, Norway; vidar.berg@nmbu.no \\ * Correspondence: abdolrahman.khezri@nmbu.no; Tel.: +47-4008-8835
}

Academic Editor: Juliette Legler

Received: 18 November 2016; Accepted: 20 January 2017; Published: 29 January 2017

\begin{abstract}
Persistent organic pollutants (POPs) are widespread in the environment and some may be neurotoxic. As we are exposed to complex mixtures of POPs, we aimed to investigate how a POP mixture based on Scandinavian human blood data affects behaviour and neurodevelopment during early life in zebrafish. Embryos/larvae were exposed to a series of sub-lethal doses and behaviour was examined at $96 \mathrm{~h}$ post fertilization (hpf). In order to determine the sensitivity window to the POP mixture, exposure models of 6 to 48 and 48 to $96 \mathrm{hpf}$ were used. The expression of genes related to neurological development was also assessed. Results indicate that the POP mixture increases the swimming speed of larval zebrafish following exposure between 48 to $96 \mathrm{hpf}$. This behavioural effect was associated with the perfluorinated compounds, and more specifically with perfluorooctanesulfonic acid (PFOS). The expression of genes related to the stress response, GABAergic, dopaminergic, histaminergic, serotoninergic, cholinergic systems and neuronal maintenance, were altered. However, there was little overlap in those genes that were significantly altered by the POP mixture and PFOS. Our findings show that the POP mixture and PFOS can have a similar effect on behaviour, yet alter the expression of genes relevant to neurological development differently.
\end{abstract}

Keywords: persistent organic pollutants; PFOS; zebrafish larvae; behavioural; neurotoxicity

\section{Introduction}

Persistent organic pollutants (POPs) refers to groups of toxic environmental chemicals with a carbon-based structure, resistant to environmental degradation and widely distributed via soil, water and air [1]. Because of their lipophilic nature, POPs tend to bioaccumulate in top predators and humans [2]. Among different classes of POPs, chlorinated, brominated and perfluorinated compounds are the most persistent compound classes, widely detected in human adipose tissue, breast milk and serum samples from all over the world [3-7].

POPs are endocrine disruptors and have been shown to have a wide range of effects including impaired reproduction, carcinogenicity, and thyroid disruption, and can promote cardiovascular 
disease and induce hepatic lesions [8,9]. Of particular concern is the lipophilic property of POPs that makes them capable of passing through biological barriers such as the placenta [10]. Indeed, several POPs are known to be neurotoxic [11-13] and have been associated with neurological diseases in children [14]. The complicated processes taking place during development make the brain and neural tissue sensitive to a variety of environmental contaminants [15,16]. Previous studies have demonstrated the ability of POPs such as perfluorooctanesulfonic acid (PFOS) to pass through the blood-brain barrier [17], causing neurotoxicity and behavioural alterations in mice, rats, and zebrafish [18-23]. As for the potential mechanisms, work in zebrafish has demonstrated that POPs such as PFOS can promote cell death in the brain following early life exposure which is then associated with altered behaviour [20]. Moreover, exposure can induce reactive oxidant species (ROS) [24] and estrogenic biomarkers [25], as well as influence the expression of genes related to metabolism and organogenesis [26]. Behavioural responses may also be related to dopaminergic deficits [27].

A large and growing body of literature has been published on the effectiveness of zebrafish as a model organism. These studies all indicate that zebrafish, due to their small size, high offspring rate, rapid development, short generation period, low cost, and transparent embryos, make a successful model organism for high-throughput screening studies [28-30]. In addition, recent work has highlighted the use of behaviour as a sensitive tool for assessing the sub-lethal effects of environmental pollutants [31-33] on both general toxicity [34] as well as neurotoxicity [31-33]. Furthermore, zebrafish have proven to be a useful model system for developmental neurotoxicity and investigating mechanistic pathways. For instance, previous studies have shown how the expression of central nervous system (CNS)-related genes in zebrafish can be impaired following exposure to different compounds [35-38].

The majority of toxicological studies have focused on the effects of single compounds only, whereas in reality we are exposed to complex mixtures of pollutants [39]. Indeed, environmentally relevant mixtures of POPs can induce biomarkers of estrogenic activity and induce cytochrome P4501A [40], impair reproductive function [40] and lead to behavioural aberrations [41,42]. However, less is known about which chemicals within these mixtures are influencing specific endpoints or how such mixtures interact on toxicological endpoints. This is a significant concern as several studies have demonstrated the potential of different compounds to have additive effects. For instance, it has been shown that a combination of $17 \alpha$-ethinyl estradiol (EE2) and dibutyl phthalate (DBP) had greater effects on gonad, liver and gill development in zebrafish compared to EE2 and DBP exposures alone [43]. Similarly, co-exposing zebrafish larvae to PFOS and nano-ZnO led to more serious thyroid-disrupting effects than exposure to PFOS alone [44]. With this in mind, we recently developed a POP mixture based on Scandinavian blood data. Initial studies have shown that our POP mixture induces ROS production in a human hepatocarcinoma cell line [45]. Furthermore, individual compounds within the POP mixture and not the total POP mixture altered the transcriptional activity of the glucocorticoid receptor in the glucocorticoid receptor redistribution assay [46].

Animals and humans are exposed to POPs in a mixture scenario. Therefore, investigating the effects of environmentally relevant POP mixtures is more realistic than the effects of a single POP. Moreover, the research to date has tended to focus on observed behavioural responses following exposure to specific compounds or a group of them, rather than investigating the mechanistic pathways involved in the behavioural response. Therefore, the aim of this study was to investigate the possible neurobehavioural effects of an environmentally relevant POP mixture and sub-mixtures, derived from Scandinavian human blood data, on zebrafish larvae. The secondary aim was to investigate the impact of the POP mixture on the expression of genes relevant to brain development and behaviour during the early life stage of zebrafish. 


\section{Results}

\subsection{Total Persistent Organic Pollutant (POP) Mixture Increased Swimming Speed}

The first part of the experiment was to screen the mixture for behavioural effects. We looked at three endpoints: the total distance moved, the total time spent active and the average swimming speed (Appendix A). From these, the average swimming speed was identified as the most robust behavioural response and used for further study. The total POP mixture at an equal concentration to that found in human plasma had no effect on larval swimming speed, while doses $20 \times, 100 \times$ and $200 \times$ higher than the human serum level resulted in significant increases in the average swimming speed $(10 \%, 38 \%$ and $61 \%$ increase, respectively) compared with controls (Figure 1A). Based on the clear response at $100 \times$ higher than human serum level, and in order to minimize any possible general toxicity, this concentration was selected for further investigation.

A
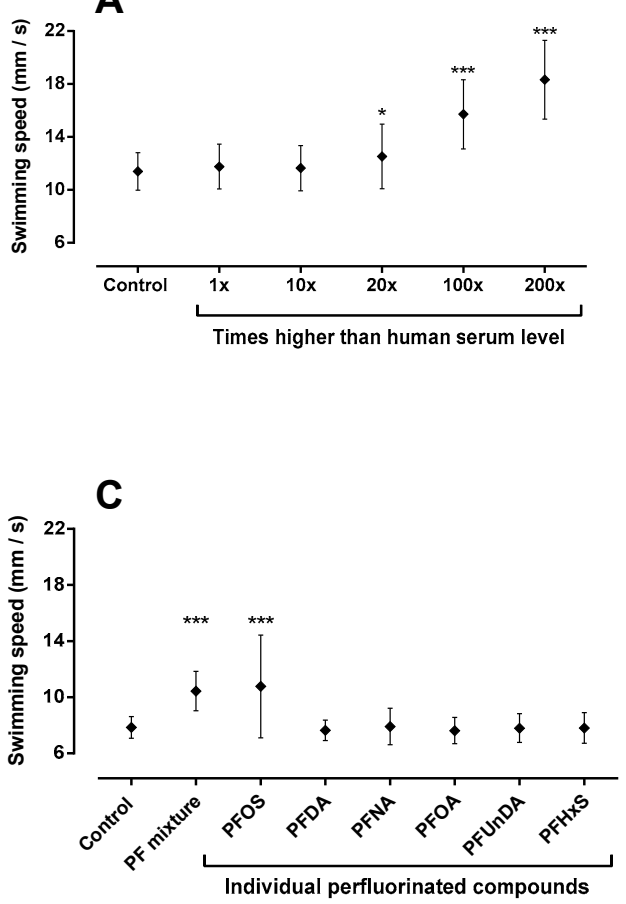

B

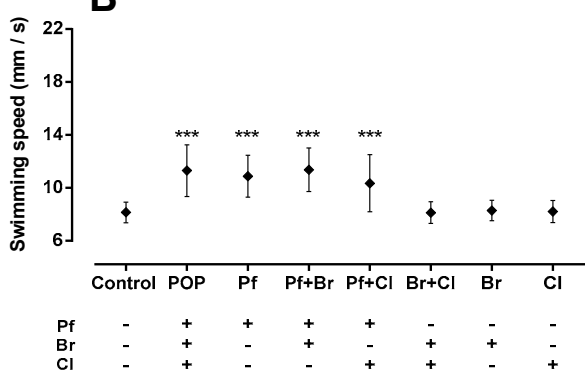

D

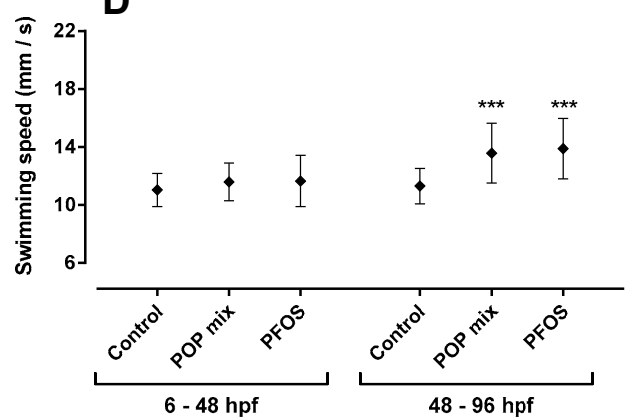

Figure 1. Swimming speed in zebrafish larvae exposed to a mixture of environmental pollutants, sub-mixtures and individual perfluorinated compounds. (A) swimming speed in zebrafish larvae upon exposure to five different concentrations of total persistent organic pollutant (POP) mixture; (B) swimming speed in zebrafish larvae upon exposure to sub-mixtures at the concentration equal to $100 \times$ higher than that found in human serum; (C) swimming speed after exposing the zebrafish to individual perfluorinated compounds $(100 \times$ human serum level) compared to PF mixture; (D) PFOS and POPs sensitivity test $(100 \times$ human serum level). (Pf) Perfluorinated mixture; (Br) Brominated mixture; $(\mathrm{Cl})$ Chlorinated mixture; $(\mathrm{Pf}+\mathrm{Br}$ ) binary mixture of perfluorinated and brominated compounds; $(\mathrm{Pf}+\mathrm{Cl})$ binary mixture of perfluorinated and chlorinated compounds; $(\mathrm{Br}+\mathrm{Cl})$ binary mixture of brominated and chlorinated compounds. (+) contained; $(-)$ not contained. Data are means \pm SD. An asterisk identifies values that are significantly different from the solvent $(0.05 \% \mathrm{DMSO})$ control $\left(\mathrm{LME},{ }^{*}=p<0.017,{ }^{* *}=p<0.0017,{ }^{* * *}=p<0.0001\right)$.

\subsection{Sub-Mixtures Containing Perfluorinated Compounds Increased Swimming Speed}

The total POP mixture consisted of three main sub-mixtures, perfluorinated, brominated and chlorinated compounds. Therefore, the next step was to identify which groups contributed to the observed behavioural response following exposure to the total mixture. It can be seen from the data 
in Figure 1B that neither the brominated or chlorinated compounds alone or in combination had any effect on swimming speed. However, exposure to mixtures containing perfluorinated compounds, at a concentration equal to $100 \times$ higher than human serum level, significantly increased swimming speed similar to what was observed following exposure to the total POP mixture.

\subsection{Perfluorooctanesulfonic Acid (PFOS) Increased Swimming Speed}

In order to identify the role of individual perfluorinated compounds in increasing the swimming speed, zebrafish embryos were exposed to the six different chemicals that made up the perfluorinated mixture. We found only PFOS significantly increased swimming speed in zebrafish larvae, similar to both the perfluorinated and total POP mixtures (Figure 1C).

\subsection{PFOS Tissue Uptake in Larvae}

We found the increase in swimming speed observed after exposure to the total POP mixture was mimicked by PFOS exposure. Based on this finding, we evaluated PFOS accumulation in $96 \mathrm{hpf}$ zebrafish larvae after exposure to the total POP mixture at a concentration equal to $100 \times$ the human serum level. Our results showed that after $96 \mathrm{~h}$ exposure, $22 \%$ of the nominal PFOS concentration was detected. Of this, $49 \%$ accumulated in the larvae, $49 \%$ remained in the exposure medium and $2 \%$ was stuck to the wells.

\subsection{8-96 hpf as Developmental Window of Sensitivity}

Based on our observed results, PFOS was the only compound that could explain the behavioural response in zebrafish larvae exposed to the total POP mixture. Next, we tested which phase of zebrafish neurodevelopmental is the most sensitive to PFOS and POP exposure. We observed that exposure from 48 to $96 \mathrm{hpf}$ significantly increased swimming speed, whereas exposure from 6 to $48 \mathrm{hpf}$ had no effect on swimming speed (Figure 1D). In addition, we observed that the insensitivity between 6 to $48 \mathrm{hpf}$ was not related to the presence of the chorion as exposure between 24 to $48 \mathrm{hpf}$ in dechorionated embryos did not increase swimming speed compared to the control (Appendix B).

\subsection{POP Mixture and PFOS Altered Gene Expression Differently}

We investigated the expression of a battery of genes involved in neurodevelopment and behaviour after exposure to the POP mixture and PFOS between 48 to $96 \mathrm{hpf}$. POP and PFOS exposure led to different gene expression profiles. Cluster analyses revealed that both PFOS $10 \times$ and PFOS $70 \times$ clustered together as did POP $10 \times$ and POP $70 \times$. In addition, the distance between POP-exposed groups and control was greater than the distance between PFOS-exposed groups and the control (Figure 2).

Although differences in gene expression profiles were detected via cluster analysis, the expression of the majority of genes remained unchanged with only eight genes including manf, crhb, hrh1, hdc, chrna7, sertb, bdnf and gabra1 being significantly affected. The POP exposure significantly affected the greatest number of genes, whereas PFOS exposure only affected one gene, hrh1. The genes manf and $h r h 1$ were significantly downregulated in both the POP $10 \times$ and $70 \times$-exposed larvae. Transcription levels of $h d c$, chrna7, sertb, bdnf and gabra1 were significantly decreased only in the POP $70 \times$ group, whereas $c r h b$ was significantly affected only in the POP $10 \times$ group. Finally, hrh1 was the only gene that was significantly downregulated by both POP $70 \times$ and PFOS $70 \times$ exposures (Figure 3 ). 


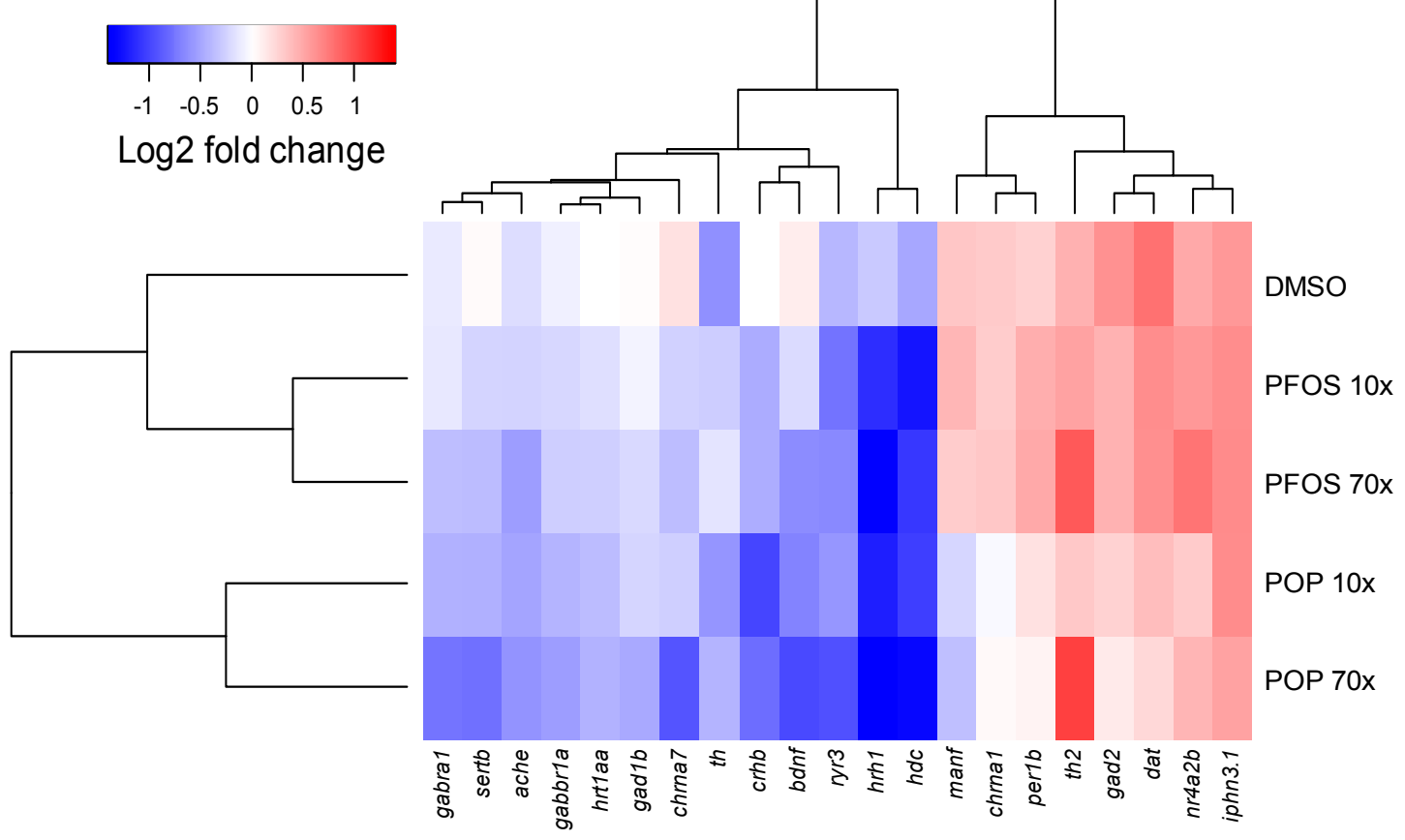

Figure 2. Euclidean distance and ward clustering on $\log 2$ normalized expression values. The heat map shows the differences in expression of 21 genes related to neurodevelopmental processes between the solvent control (0.05\% DMSO) and exposed samples in $96 \mathrm{hpf}$ zebrafish. Cluster analysis was performed on $\log 2$ expression values of five biological replicates.

\section{Gene expression}

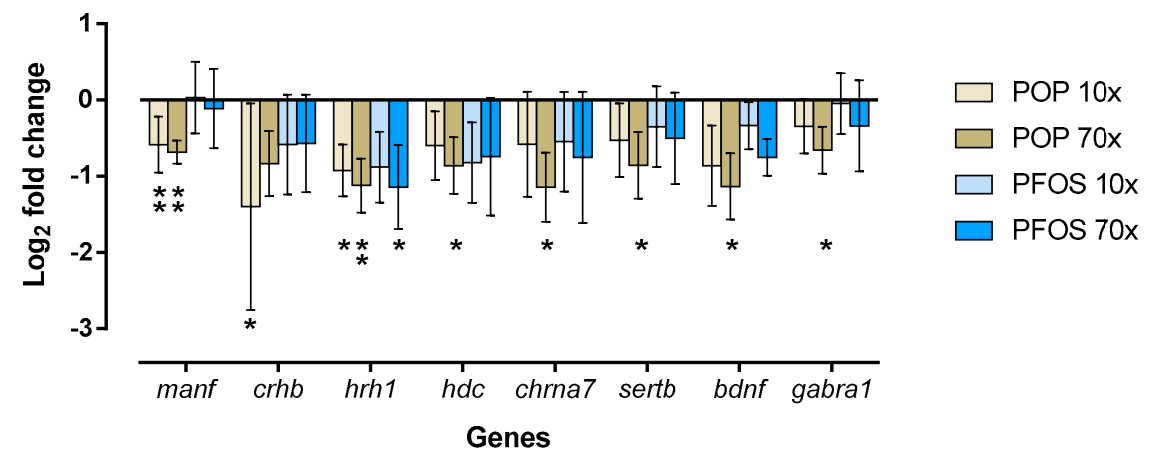

Figure 3. Transcription levels in genes relevant to behaviour following POP mixture and PFOS exposure. The line at zero indicates the gene expression in control groups (DMSO 0.05\%). Data are presented as mean \pm SD relative to control. An asterisk identifies genes expression levels that were significantly different from the solvent control (one-way ANOVA test, ${ }^{*}=p<0.05,{ }^{* *}=p<0.005$ ).

\section{Discussion}

Our aim was to determine whether a human POP mixture based on human blood levels from the Scandinavian population could induce behavioural effects following developmental exposure, using zebrafish as a model vertebrate system. Our results indicated that the total POP mixture significantly affected the swimming behaviour in zebrafish larvae starting at a concentration $20 \times$ higher than that found in human serum. Further investigations revealed that PFOS alone could mimic the behavioural response observed following exposure to the POP mixture. However, although the results from gene expression analysis revealed that both the POP mixture and PFOS altered the regulation of CNS-related genes, there was limited overlap in those genes significantly affected. Our work highlights the potential 
developmental neurotoxicity of a POP mixture relevant to humans. To date, very little attention has been paid to the potency of mixtures of environmental pollutants on the induction of neurobehavioural toxicity. Previous work would suggest the results of single compounds are not fully translatable to mixture scenarios, mainly because of unknown interactions between different chemicals in complex mixtures [47]. We found the POP mixture increased the swimming speed in zebrafish larvae in a dose-dependent manner. This behavioural effect was associated with the perfluorinated compounds within the mixture, more specifically with PFOS. This result could be explained by the fact that PFOS was the compound with the highest concentration in the total and perfluorinated mixtures (5.46 $\mu \mathrm{M}$ in $100 \times$ mixtures), compared with PFOA $(1 \mu \mathrm{M}$ in $100 \times$ mixture) which was the second most concentrated compound. Of note, PFOS alone increased swimming speed to a similar extent as the total POP mixture, which suggests PFOS toxicity was not influenced by other compounds in the POP mixture. Previous studies have shown a hyperactive behaviour upon PFOS exposure in both zebrafish and rodents. For instance, zebrafish larvae exposed to $1.85 \mu \mathrm{M}$ PFOS developed spontaneous activity and persistent hyperactivity [27]. Another study reported that PFOS in a wide range of concentrations $(0.5$ to $8 \mu \mathrm{M})$ increases the swimming speed in both 5 and $6 \mathrm{dpf}$ zebrafish larvae [20]. It has also been shown that chronic prenatal exposure to PFOS $(0.5 \mu \mathrm{M})$ for 120 days in zebrafish is able to increase the swimming speed in both parents and F1 larvae [18]. Similarly, mice exposed to $3 \mathrm{mg} / \mathrm{kg} /$ day PFOS displayed spontaneous activity [27] whereas other rodent studies have found that PFOS decreases locomotor activity $[48,49]$.

Regarding the increase in swimming speed, we found that $48-96 \mathrm{hpf}$ is the sensitive window for the total POP mixture and PFOS exposure, as exposures before $48 \mathrm{hpf}$ had no effect on swimming speed. These results match those observed in earlier studies. For example, it has been shown that zebrafish larvae exposed to PFOS from 49 to $73 \mathrm{hpf}$ had higher swimming speeds compared with groups exposed before $49 \mathrm{hpf}$ and after $73 \mathrm{hpf}$ [20]. Moreover, it has been reported that $16 \mu \mathrm{M}$ PFOS exposure between 48 to $96 \mathrm{hpf}$ in zebrafish larvae resulted in noticeable deformities (uninflated swim bladder, less developed gut, and curved spine), whereas larvae developmentally exposed to PFOS from 8 to $48 \mathrm{hpf}$ did not develop any distinct deformities, even after exposure to $32 \mu \mathrm{M}$ [26]. Another study reported that PFOS exposure before $48 \mathrm{hpf}$ had no effect on the development of the swim bladder, while exposure after $48 \mathrm{hpf}$ resulted in swim bladder deformities in 50\% of the zebrafish larvae [50]. Different hypotheses have been suggested regarding the sensitivity of zebrafish larvae to PFOS exposure. For instance, this window of sensitivity might be related to the development of estrogenic receptors, which begin to be expressed after $48 \mathrm{hpf}$ in zebrafish larvae, and could mediate PFOS toxicity [26]. However, although PFOS exposure does produce estrogenic effects in zebrafish [25], we have previously found exposure to $10 \mathrm{nM}$ of the xenoestrogen $17 \alpha$-ethinylestradiol (EE2) has no effect on behaviour at $96 \mathrm{hpf}$ even though we detected an elevation in the expression of estrogenic response genes [51]. Furthermore, it seems that PFOS toxicity is not related to the presence of the chorion. Previous work has demonstrated that PFOS accumulates in 6 hpf-exposed embryos two hours after exposure, but absorption and accumulation of PFOS is accelerated in larvae after $48 \mathrm{hpf}$ [20]. This increase in absorption at later life stages may explain why larvae were more sensitive to PFOS exposure at the later life stage.

We evaluated gene transcription after POP and PFOS exposure during the $48-96 \mathrm{hpf}$ window. As previously reviewed $[29,52,53]$, the different regions of the zebrafish brain are almost developed by $48 \mathrm{hpf}$ and between $48-96 \mathrm{hpf}$ the developmental processes for different neurotransmitter-expressing neurons is accelerating. Therefore, we hypothesized that those CNS processes that start to develop after 48 hpf in zebrafish larvae could mediate the POP and PFOS behavioural toxicity. Although both POP $70 \times$ and PFOS $70 \times$ exposure significantly increased the swimming speed, we found only one mutually affected gene ( $h r h 1)$ between these exposure groups, whereas other genes involved in dopaminergic (manf), histaminergic ( $h d c)$, serotonergic (sertb), cholinergic (chrna7), GABAergic (gabra1), stress $(c r h b)$ and neural maintenance $(b d n f)$ signalling were exclusively affected in POP-exposed groups. This could be explained by presence of brominated, chlorinated and perfluorinated compounds within 
the mixture. Similarly, mixtures of polycyclic aromatic hydrocarbons (PAHs) had limited overlap on gene expression compared to individual compounds in rat liver [54]. The cluster analysis confirmed that the POP exposure altered the gene expression profile in a different manner compared with PFOS. This would suggest that the genes assessed here were either not involved in the observed behavioural responses or that PFOS has a different molecular pathway leading to the observed behavioural effects.

Previous studies have implemented the dopaminergic and serotonergic systems in the neurotoxicity of PFOS, but we found no clear evidence that these systems explained the increase in swimming speed in the current study. For example, PFOS increased the level of serotonin in different regions of the rat brain [55] and impaired the dopaminergic system in both mice and zebrafish [22,27]. Moreover, it has been shown that PFOS exposure upregulated $c r h b$, which is a marker of the stress response [56]. However, the dopaminergic genes sertb, and crhb were not significantly affected by PFOS in this study. Additionally, although gene expression was more influenced by exposure to $70 \times$ compared to $10 \times$ of the POP mixture, including genes involved in inhibitory signaling pathways (sertb, gabra1) [57,58], it is unclear which systems may be behind the behavioural effects observed in the current study.

One of the main objectives of toxicity testing is to determine the lowest effect concentrations. Gene analyses data revealed that manf, $c r h b$ and $h r h 1$ genes were significantly downregulated upon POP exposure, even at a concentration only $10 \times$ higher than human serum level. manf is a dopaminergic neurotrophic factor that protects dopaminergic neurons from neurotoxic damage [59] and plays a supportive role in cell viability [60]. In addition to the stress response, crhb also plays an important role in thyroid-stimulating hormone (TSH) secretion [61]. There was also significant downregulation of $c r h b$ in this study, thereby suggesting a possible disruptive effect of the POP mixture on the hypothalamic-pituitary-interrenal (HPI)/hypothalamic-pituitary-adrenal (HPA), and hypothalamic-pituitary-thyroid (HPT) axis. Hrh1 is a histamine receptor expressed widely in the CNS, and also regulates the immune response [62]. Therefore, although no behavioural effect was observed following the $10 \times$ exposure, changes in gene expression were observed at concentrations close to the human scenario. Further research is needed to explore the biological significance of these changes in gene expression and which compounds from the POP mixture are responsible for these changes.

Based on our results, exposure to a mixture of brominated and/or chlorinated compounds had no effect on swimming speed. Similarly, it has been reported that brominated compounds including BDE 47, 99, 100, 153, 154, 209 and HBCD, at concentrations within the range used in current study, had no significant effect on locomotor behaviour in $5 \mathrm{dpf}$ zebrafish larvae [63]. Although some brominated and chlorinated compounds are known to influence larval zebrafish behaviour in contrast to our results, these compounds are either not in our mix or the effects were found at concentrations higher than those used in the current study $[42,64]$.

We used larval zebrafish to assess a human-based POP mixture for behavioural effects. Differences in larval locomotor behaviour using the light/dark assay are generally associated with the level of anxiety [65], suggesting our mixture could lead to alterations in anxiety within humans. The concentrations tested were of relevance to humans, as we found effects levels only marginally higher (i.e., 10 $\times$ ) than those found in human blood serum. Here it is noted that the human-based POP mixture was based on the mean values within Scandinavians. Therefore, some individuals will have higher values than the mean, and the levels of environmental pollutants within humans varies between different countries and tends to be lower in more developed countries [66]. Furthermore, we could only recover $22 \%$ of the nominal value for PFOS at $96 \mathrm{hpf}$. It is unclear where the remaining $78 \%$ went, but the values attained per embryo (63 ng following exposure to $5.5 \mu \mathrm{M}$ PFOS) were very similar to those values obtained by [20] following exposure between 0 and 5 days post fertilization (66 ng/embryo following exposure to $8 \mu \mathrm{M}$ PFOS). 


\section{Materials and Methods}

\subsection{Mixtures and Chemicals}

The POP mixtures were designed and made by the Norwegian University of Life Sciences, Oslo, and described in [67]. Relevant compounds and their levels in human plasma of a Scandinavian population were identified, and seven different mixtures were prepared and used in the current study, including; (1) total POP mixture containing perfluorinated, brominated and chlorinated compounds; (2) perfluorinated mixture (Pf); (3) brominated mixture (Br); (4) chlorinated mixture $(\mathrm{Cl})$; (5) perfluorinated and brominated mixture $(\mathrm{Pf}+\mathrm{Br})$; (6) perfluorinated and chlorinated mixture $(\mathrm{Pf}+\mathrm{Cl})$; and $(7)$ brominated and chlorinated mixture $(\mathrm{Br}+\mathrm{Cl})$. The compounds were mixed in concentration ratios relevant to the human serum level. The intention was that the dose of each mixture reflected the human plasma level of corresponding chemicals within that mixture. The chemicals included in the mixtures and their respective concentrations are shown in Table S1. All polybrominated diphenyl ethers (PBDEs), polychlorinated biphenyls (PCBs) and other organochlorines were originally purchased from Chiron As (Trondheim, Norway). Hexabromocyclododecane (HBCD) and all perfluorinated compounds (PFCs) were obtained from Sigma-Aldrich (St. Louis, MO, USA), except PFHxS which was from Santa Cruz (Dallas, TX, USA). All stock solutions were formed in pure DMSO (Sigma-Aldrich).

\subsection{Zebrafish Maintenance and Breeding}

Adult AB strain zebrafish (Danio rerio) were housed with a 14:10 h light:dark cycle period in a carbon-filtered flow-through system. System water was kept at $28 \pm 1{ }^{\circ} \mathrm{C}$ and prepared by adding $15.5 \mathrm{~g}$ of Instant Ocean ${ }^{\circledR}$ salt, $5.3 \mathrm{~g}$ of sodium bicarbonate and $1.5 \mathrm{~g}$ of calcium chloride per $100 \mathrm{~L}$ of tap water to attain a $\mathrm{pH}$ of 7.5-7.6 and conductivity of $500 \mu \mathrm{S} / \mathrm{cm}$. Fish were fed daily, twice with Artemia and once with formulated feed (SDS 400, Essex, UK) and kept at a density equal to seven fish/L. For egg production, male and female adult zebrafish were held in breeding tanks equipped with a barrier and spawning net. The barriers were removed shortly after the onset of light in the morning and the fish paired for $30 \mathrm{~min}$. Eggs collected from the breeding tanks were rinsed and kept in autoclaved system water at $28^{\circ} \mathrm{C}$ until exposure.

\subsection{Exposure Scenario}

The study was performed at the Section for Experimental Biomedicine at the Norwegian University of Life Sciences in Oslo, Norway. The unit is licensed by the Norwegian Food Inspection Authority (NFIA) and accredited by the Association for Assessment and Accreditation of Laboratory Animal Care (2014/225976). The study (2013/39783-2) was approved on 20/08/2013 by the unit's animal ethics committee (Institutional Animal Care and Use Committee/IACUC) and NFIA.

Fertilized and healthy embryos at approximately $6 \mathrm{hpf}$ were selected using a stereo microscope. Equal numbers of embryos for each treatment were distributed in a checker-box pattern across 96-well plates (Thermo Fisher Scientific, Roskilde, Denmark) (one embryo/well) and exposed statically in $200 \mu \mathrm{L}$ of media. The final concentration of DMSO in all test concentrations and the solvent control was $0.05 \%$. First, embryos were exposed separately to all seven mixtures over the concentration range $1 \times$ to $200 \times$ higher than human serum levels (three replicates). These concentrations were considered non-teratogenic based on a maximum mortality/deformity rate of $10 \%$ in any one group. These experiments were then followed by exposing the zebrafish embryos to individual chemicals from the PF mixture, including: perfluorooctanoic acid (PFOA), perfluorooctanesulfonic acid potassium salt (PFOS), perfluorodecanoic acid (PFDA), perfluorononanoic acid (PFNA), perfluorohexane sulfonate potassium salt (PFHxS), perfluoroundecanoic acid (PFUnDA) and the perfluorinated mixture itself at a concentration equal to $100 \times$ higher than human serum levels (three replicates). After each exposure, plates were placed into sealed transparent plastic bags and kept at $28^{\circ} \mathrm{C}$ on a $14: 10 \mathrm{~h}$ light: dark cycle until $96 \mathrm{hpf}$, when behavioural tests were undertaken. 


\subsection{Locomotor Activity}

Behavioural assays were conducted on 96 hpf larvae during a light/dark/light cycle using a Viewpoint Zebrabox (Viewpoint Life Science, Lyon, France). This system consists of a 25-frame per second camera equipped with an infrared filter that is capable of tracking zebrafish movement through its supplied software (Video-Track software, ViewPoint Life Science, France). All tests were performed at $28{ }^{\circ} \mathrm{C}$ between 09:00 and 10:30. The test consisted of $10 \mathrm{~min}$ of acclimation when the light intensity was set to $100 \%$ (these data were excluded from final analyses), followed by a further $10 \mathrm{~min}$ of $100 \%$ light, $10 \mathrm{~min}$ of complete darkness, and a final $10 \mathrm{~min}$ of $100 \%$ light. Only locomotor activity during the dark period was analysed, as movement during the lighted periods was minimal as expected for this life stage [68]. Zebrafish larvae were distinguished from the background by introducing a 30-pixel threshold difference within the tracking software. In addition, short and large movements were defined as 5 and $8 \mathrm{~mm}$ per sec in the protocol, respectively. The total distance moved $(\mathrm{mm})$ and the total time spent active (s) were recorded every $60 \mathrm{~s}$. From this data, the mean swimming speed $(\mathrm{mm} / \mathrm{s})$ was calculated. Following locomotor assessment, larvae were evaluated using a microscope for any dead or malformed (spinal/tail aberrations, yolk sac or cardiac edema, aberrations in pigmentation, and loss of equilibrium) individuals to be excluded from behavioural analyses.

\subsection{PFOS Tissue Uptake in Larvae}

The analyses of embryos, medium and wells was done at the laboratory of Environmental Toxicology at the Norwegian University of Life Sciences. The laboratory is accredited by the Norwegian accreditation for testing PFOS in biological material according to the requirements of the NS-EN ISO/IEC 17025 (TEST 137). The PFOS concentrations in the exposure media and whole-body tissues of zebrafish larvae were measured in embryos exposed from 6 to $96 \mathrm{hpf}$ to the total POP mixture at a concentration equal to $100 \times$ higher than in human serum. Six zebrafish larvae from six individual wells were pooled as one sample and the exposure media was taken from the corresponding six wells ( $200 \mu \mathrm{L} /$ well). Each well was then rinsed by methanol, which was then collected to measure any chemicals that may have resided on the wall of the well. PFOS was analysed according to [69] and references therein. Both linear and branched PFOS were included in analyses as recommended by [70]. The samples were extracted with methanol and clean up was accomplished using active carbon (EnviCarb, Supelco, Zwijndrecht, The Netherlands). Analysis was performed by the separation of compounds on a high-performance liquid chromatographer (HPLC) with a Discovery C18 column, connected to a C18 pre-column (Supelco, Sigma-Aldrich) and detection with liquid chromatography tandem mass spectrometry (MS-MS) (API 3000, LC/MS/MS System). The details of the analytical quality system have been described in [71]. Briefly, every analytical series included three procedural blanks (solvents), one blind (non-spiked clean), and two spiked clean samples for recoveries. The quality control parameters were within the accepted ranges for the method.

\subsection{Developmental Sensitivity Test}

In order to link the observed behavioural response with the neurodevelopmental stages, we exposed zebrafish embryos at two different time points. Zebrafish embryos were exposed to PFOS and then a total POP mixture at a concentration equal to $100 \times$ higher than human serum level from 6 to $48 \mathrm{hpf}$ before being washed three times with autoclaved system water and exposed to $200 \mu \mathrm{L}$ of the vehicle solution only (DMSO 0.05\%) from 48 to 96 hpf. Simultaneously, on the same plate, another group of zebrafish embryos were exposed to $200 \mu \mathrm{L}$ of vehicle solution during the first $48 \mathrm{~h}$ and then the exposure followed between $48-96$ hpf by adding PFOS or the total POP mixture at $100 \times$ higher than the human serum level. This experiment was repeated in triplicate. 


\subsection{Gene Transcription Analysis}

To determine the mRNA expression induced by the total POP mixture and PFOS, zebrafish larvae were exposed between $48-96 \mathrm{hpf}$. Concentrations were adjusted to $10 \times$ and $70 \times$ human serum level as the highest dose at which had no effect on swimming speed (HNSS) or the lowest dose at which there was a significant increase in swimming speed (LISS), respectively (Appendix C). Primers were designed to span exon-exon boundaries using Primer3-based algorithms available at (https://www.ncbi.nlm. nih.gov/tools / primer-blast/) and tested for dimers and efficiency using Vector NTI ${ }^{\circledR}$ advance software version 11 for windows and melting curve, respectively (Table S2). Total RNA was isolated from a pool of 10 embryos from each treatment using Trizol agent (Invitrogen, Carlsbad, CA, USA) and following the manufacturers' instruction. RNA concentration was measured by nanodrop, cDNA was prepared from $1 \mu \mathrm{g}$ of DNase-treated total RNA using Superscript III reverse transcriptase (Invitrogen) and random hexamer primers according to product specifications. Quantitative PCR (qPCR) was carried out on a LightCycler ${ }^{\circledR} 96$ Real-Time PCR system (Roche, Mannheim, Germany) using LightCycler ${ }^{\circledR}$ 480 SYBR Green I Master (Roche). Each cDNA sample was analysed in duplicate and composed of $5 \mu \mathrm{L}$ mastermix, $2 \mu \mathrm{L}$ primer mix ( $5 \mu \mathrm{M}$ of each of forward and reverse), and $3 \mu \mathrm{L}$ of each $10 \times$ diluted cDNA sample in a total volume of $10 \mu \mathrm{L}$. The cycling parameters were $10 \mathrm{~min}$ pre-incubation at $95^{\circ} \mathrm{C}$, followed by 45 cycles of amplification at $95^{\circ} \mathrm{C}$ for $10 \mathrm{~s}, 60^{\circ} \mathrm{C}$ for $10 \mathrm{~s}$ and $72{ }^{\circ} \mathrm{C}$ for $15 \mathrm{~s}$, followed by a melting curve from $60^{\circ} \mathrm{C}$ to $95^{\circ} \mathrm{C}$. qPCR assay was performed for five biological replicates. After the assessment of candidate reference genes ( $h p r t, r p s 18$, ef1 $\alpha, h m b s$ and bactin) using the online RefFinder analysis available at (http:/ / fulxie.0fees.us/), and based on the Genorm algorithm, rps18 and ef1 $\alpha$ were considered the most stable housekeeping genes for all exposure groups. The expression of each target gene transcript was normalized to the housekeeping genes and the fold change was calculated using the $\Delta \Delta C_{t}$ method, using the geometric averaging of the two reference genes [72].

\subsection{Statistical Analyses}

Locomotor activity data were transferred to R Studio (RStudio Team 2015, version 0.99 .473 for windows, Boston, MA, USA, available at: http://www.rstudio.com/) for behavioural analyses. To test the effect of the total POP mixture, sub-mixtures and individual compounds on locomotor activity, a linear mixed effect model (LME) was employed with distance moved, time spent swimming or swimming speed as the dependent variable, mixture/compound concentration as a categorical independent variable, and test replicate as a random effect. Examination of the residual plots verified that no systematic patterns occurred in the errors (e.g., q-q plots). To assess individual doses to the controls, we used the contrast results provided within R. Due to multiple comparisons of the same data set (i.e., the same individuals were used to assess three behavioural endpoints, distance moved, time active, and swimming speed), the results were Bonferroni corrected to avoid Type I errors. Therefore, significance was assigned at $p<0.017$ (i.e., 0.05/3). Gene expression data were analysed using one-way ANOVA test followed by Dunnett's post hoc test and the limit of significance was set at $p<0.05$. Data were plotted using GraphPad Prism version 7.02 for Windows, (GraphPad Software, San Diego, CA, USA).

\section{Conclusions}

We aimed to assess the possible neurobehavioural toxicity of an environmentally relevant mixture of persistent organic pollutants (POPs), which was constructed based on Scandinavian human blood data. This study has shown that exposure to a complex mixture consisting of brominated, chlorinated and perfluorinated compounds, significantly affected the swimming speed of zebrafish larvae. The effect was related to the perfluorinated compounds, exclusively with perfluorooctanesulfonic acid (PFOS). These behavioural effects could not be associated with the difference in gene expression. Since behaviour is a complicated phenomenon, further work should investigate whether the POP mixture and PFOS affect additional molecular and physiological processes 
related to behaviour such as the sensory system or endocrine hormone levels, and investigate the functional role of the genes affected by the POP mixture.

Supplementary Materials: Supplementary materials can be found at www.mdpi.com/1422-0067/18/2/291/s1.

Acknowledgments: The authors thank Ana Carolina Sulen Tavara, Arturas Kavaliauskis, and the weekend staff at the Norwegian University of Life Sciences zebrafish facility for fish husbandry, and Jessica Legradi for providing sequences for the qPCR experiments.

Author Contributions: Abdolrahman Khezri and Thomas W. K. Fraser conceived and designed the experiments; Abdolrahman Khezri performed the experiments; Abdolrahman Khezri, Thomas W. K. Fraser and Jorke H. Kamstra analysed the data; Rasoul Nourizadeh-Lillabadi, Jorke H. Kamstra and Vidar Berg contributed analysis tools; Abdolrahman Khezri wrote the paper. Karin E. Zimmer prepared the POP mixture. Erik Ropstad and Karin E. Zimmer have taken part in the planning and supervision and all authors contributed to drafting and reviewing the manuscript.

Conflicts of Interest: The authors declare no conflict of interest.

$\begin{array}{ll}\text { Abbreviations } & \\ \text { BDE } & \text { Brominated diphenyl ethers } \\ \text { BDNF } & \text { Brain-derived neurotrophic factor } \\ \text { CHRNA7 } & \text { Cholinergic receptor nicotinic alpha } 7 \text { subunit } \\ \text { CNS } & \text { Central nervous system } \\ \text { CRHB } & \text { Corticotropin releasing hormone Beta } \\ \text { DMSO } & \text { Dimethyl sulfoxide } \\ \text { DPF } & \text { Day post fertilization } \\ \text { GABRA1 } & \text { Gamma-Aminobutyric Acid Type A Receptor Alpha1 Subunit } \\ \text { HDC } & \text { Histidine decarboxylase } \\ \text { HPF } & \text { Hour post fertilization } \\ \text { HRH1 } & \text { Histamine Receptor H1 } \\ \text { LME } & \text { Linear mixed effect } \\ \text { MANF } & \text { Mesencephalic astrocyte-derived neurotrophic factor } \\ \text { PBDE } & \text { Polybrominated diphenyl ethers } \\ \text { PCB } & \text { Polychlorinated biphenyl } \\ \text { PFDA } & \text { Perfluorodecanoic acid } \\ \text { PFHxS } & \text { Perfluorohexane sulfonate } \\ \text { PFNA } & \text { Perfluorononanoic acid } \\ \text { PFOA } & \text { Perfluorooctanoic acid } \\ \text { PFOS } & \text { Perfluorooctanesulfonic acid } \\ \text { PFUnDA } & \text { Perfluoroundecanoic acid } \\ \text { POPS } & \text { Persistent organic pollutants } \\ \text { ROS } & \text { Reactive oxygen species } \\ \text { SERTB } & \text { Serotonin transporter B }\end{array}$




\section{Appendix A}

Table A1. Distance moved and swimming time in $96 \mathrm{hpf}$ zebrafish larvae exposed to total POP mixture, sub mixtures and individual mixtures.

\begin{tabular}{|c|c|c|c|c|c|c|c|c|c|c|c|c|}
\hline \multirow{2}{*}{ Exposure Groups } & \multicolumn{6}{|c|}{ Distance Moved $(\mathrm{mm} / 10 \mathrm{~min})$} & \multicolumn{6}{|c|}{ Swimming Time (s/10 min) } \\
\hline & Control & $1 \times$ & $10 \times$ & $20 \times$ & $100 \times$ & $200 \times$ & Control & $1 \times$ & $10 \times$ & $20 \times$ & $100 \times$ & $200 \times$ \\
\hline Total POPs & $742.1 \pm 290.2$ & $32.5 \pm 373.4$ & $.9 \pm 303.9$ & $783.2 \pm 271.7$ & $722.1 \pm 366.2$ & $596.3 \pm 40 \mathrm{C}$ & $6.1 \pm 27.1$ & $67.2 \pm 31.9$ & $.1 \pm 25.3$ & $4.6 \pm 23.8$ & $48.3 \pm 26.8^{* *}$ & $34 \pm 24.3^{* * *}$ \\
\hline Pf & $0.8 \pm 345.3$ & $730.5 \pm 371.7$ & $774.4 \pm 385.3$ & $722.8 \pm 370$ & $743.6 \pm 306.7$ & $552.4 \pm 367.4^{*}$ & $61.7 \pm 29.8$ & $61 \pm 32.3$ & $6.2 \pm 34.6$ & $60.2 \pm 31.7$ & $47.6 \pm 23.9 *$ & $32.6 \pm 24.1^{* * *}$ \\
\hline $\mathrm{Pf}+\mathrm{Br}$ & $4.8 \pm 420.4$ & $720.4 \pm 326.2$ & $672.8 \pm 368.9$ & $834.1 \pm 331.1$ & $657.2 \pm 330.9$ & $457.2 \pm 321^{* * *}$ & $66.9 \pm 35.3$ & $63.3 \pm 29.3$ & $55.7 \pm 31.3$ & $69.2 \pm 28.4$ & $42.9 \pm 24^{* * *}$ & $25.4 \pm 18.5^{* * *}$ \\
\hline $\mathrm{Pf}+\mathrm{Cl}$ & $667.4 \pm 330.8$ & $689.4 \pm 305.7$ & $675.9 \pm 276.3$ & $669.2 \pm 313.3$ & $632.4 \pm 369.2$ & $494.5 \pm 313.8 *$ & $57.8 \pm 27.3$ & $59 \pm 27$ & $57.3 \pm 24.7$ & $54.9 \pm 24.4$ & $42 \pm 28.7^{*}$ & $30.7 \pm 23.9^{* * *}$ \\
\hline $\mathrm{Br}$ & $2.5 \pm 309.6$ & $562.6 \pm 238.3$ & $614.9 \pm 283.4$ & $622.8 \pm 293.6$ & $656.8 \pm 238.3$ & $679.6 \pm 297.2$ & $60.3 \pm 30.1$ & $52.4 \pm 23.2$ & $56.9 \pm 27.3$ & $56.7 \pm 27.2$ & $59.9 \pm 23.4$ & $62.6 \pm 27.8$ \\
\hline $\mathrm{Cl}$ & $770.6 \pm 341.4$ & $684.1 \pm 310.5$ & $711.9 \pm 269.8$ & $738.1 \pm 330.8$ & $889.7 \pm 374.6$ & $838.8 \pm 403.6$ & $68.4 \pm 30.1$ & $58 \pm 27.2$ & $60.5 \pm 24.4$ & $64.1 \pm 29.8$ & $77 \pm 32.6$ & $71.3 \pm 33.7$ \\
\hline $\mathrm{Br}+\mathrm{Cl}$ & $677.7 \pm 338.2$ & $627.4 \pm 319.9$ & $641.7 \pm 342.3$ & $654.4 \pm 329.8$ & $640 \pm 327.3$ & $706.4 \pm 277.5$ & $62.6 \pm 31.9$ & $58.4 \pm 31.4$ & $58.1 \pm 32.8$ & $58.4 \pm 29.4$ & $57.7 \pm 30.6$ & $64.2 \pm 26.9$ \\
\hline
\end{tabular}

The distance moved and swimming time by zebrafish larvae at $96 \mathrm{hpf}$ after exposure to the total persistent organic pollutants (POP) mixture and different sub-mixtures at different perfluorinated and chlorinated compounds; $(\mathrm{Br})$ brominated mixture; $(\mathrm{Cl})$ chlorinated mixture; $(\mathrm{Br}+\mathrm{Cl})$ co-mixture of brominated and chlorinated compounds. Data presented as means \pm SE. Asterisk indicates a significant exposure effect compared to the control (LME, ${ }^{*}=p<0.017^{* *}=p<0.0017,{ }^{* * *}=p<0.0001$ ). 


\section{Appendix B}

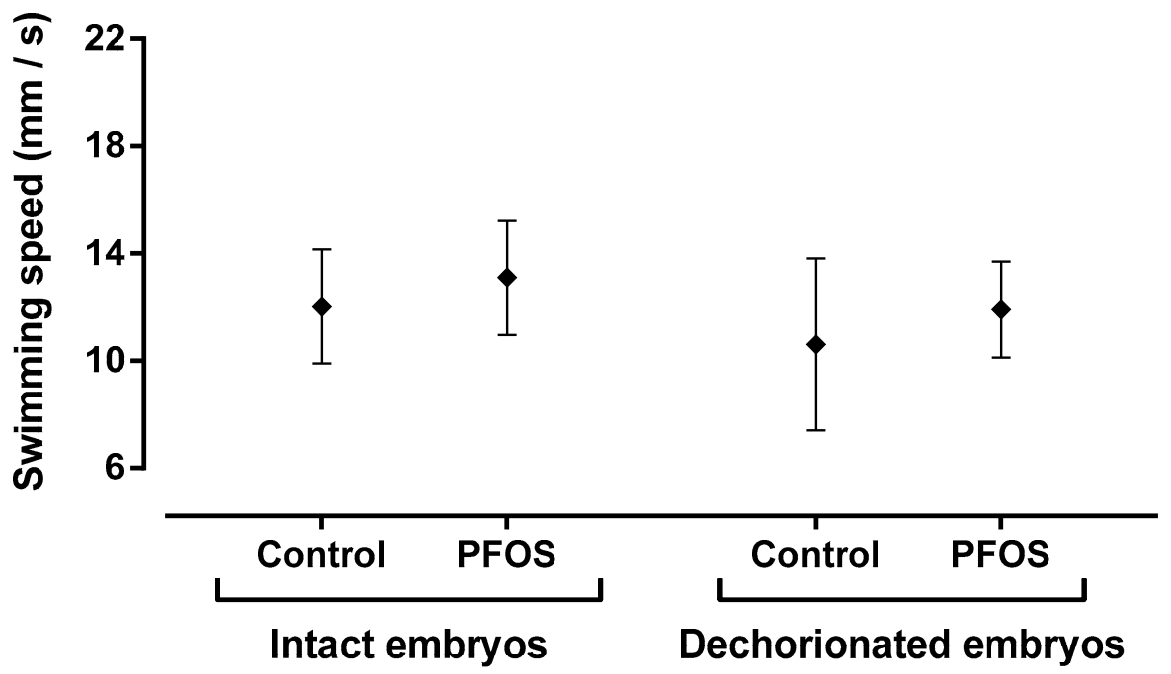

Figure A1. Swimming speed at $96 \mathrm{hpf}$ in zebrafish larvae. Dechorionated and intact zebrafish embryos were exposed to perfluorooctanesulfonic acid (PFOS) $(100 \times$ human serum level) between 24 to $48 \mathrm{hpf}$. Data presented as mean $\pm \mathrm{SD}$.

\section{Appendix C}

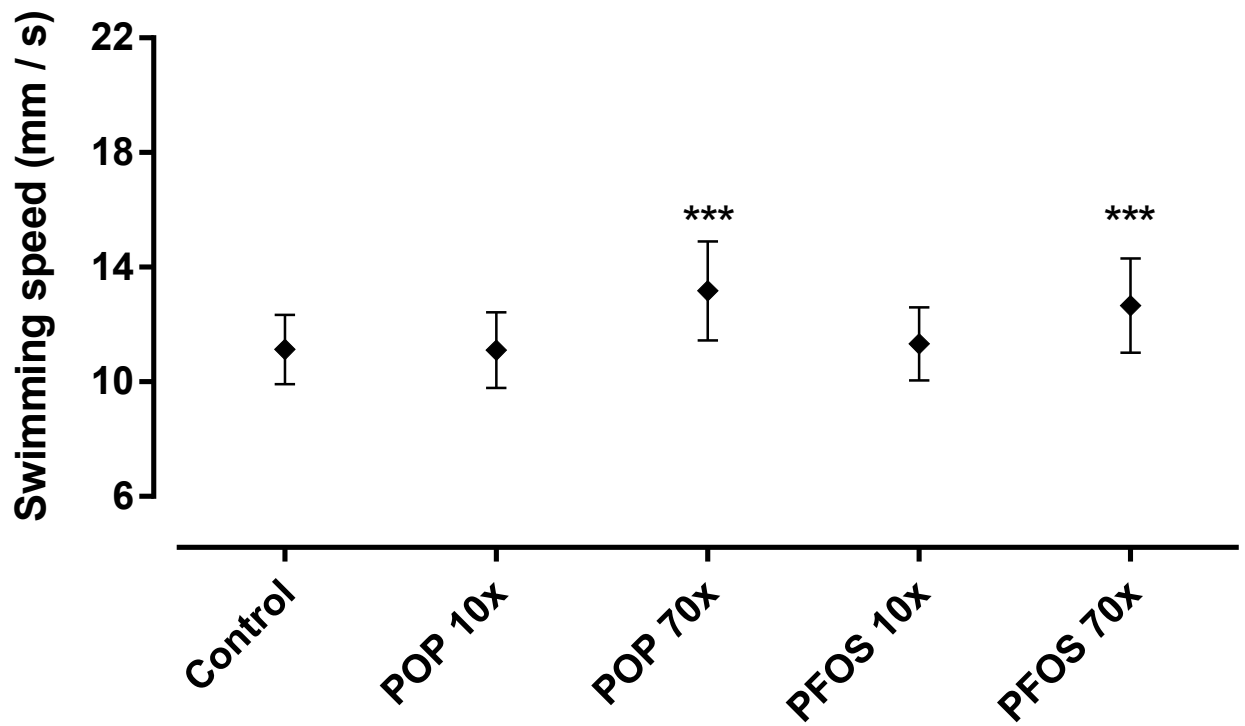

Figure A2. Swimming speed in $96 \mathrm{hpf}$ zebrafish larvae after exposure to POP and PFOS at two different concentrations $(10 \times$ and $70 \times$ higher than human serum level) between 48 to $96 \mathrm{hpf}$. In order to expose the zebrafish for gene expression analyses, concentrations were adjusted to $10 \times$ and $70 \times$ human serum level as the highest dose at which there was no significant effect on swimming speed (HNSS) or the lowest dose that consistently and significantly increased the swimming speed (LISS), respectively. Data presented as mean $\pm \mathrm{SD}$. An asterisk indicates a significant difference between the exposure group and the solvent control $\left(\mathrm{LME},{ }^{*}=p<0.017,{ }^{* *}=p<0.0017,{ }^{* * *}=p<0.0001\right)$. 


\section{References}

1. Hung, H.; Katsoyiannis, A.A.; Guardans, R. Ten years of global monitoring under the stockholm convention on persistent organic pollutants (POPs): Trends, sources and transport modelling. Environ. Pollut. 2016, 217, 1-3. [CrossRef] [PubMed]

2. Daley, J.M.; Paterson, G.; Drouillard, K.G. Bioamplification as a bioaccumulation mechanism for persistent organic pollutants (POPs) in wildlife. Rev. Environ. Contam. Toxicol. 2014, 227, 107-155. [PubMed]

3. Kim, S.; Park, J.; Kim, H.J.; Lee, J.J.; Choi, G.; Choi, S.; Kim, S.; Kim, S.Y.; Moon, H.B.; Kim, S.; et al. Association between several persistent organic pollutants and thyroid hormone levels in serum among the pregnant women of korea. Environ. Int. 2013, 59, 442-448. [CrossRef] [PubMed]

4. Knutsen, H.K.; Kvalem, H.E.; Thomsen, C.; Frøshaug, M.; Haugen, M.; Becher, G.; Alexander, J.; Meltzer, H.M. Dietary exposure to brominated flame retardants correlates with male blood levels in a selected group of norwegians with a wide range of seafood consumption. Mol. Nutr. Food Res. 2008, 52, 217-227. [CrossRef] [PubMed]

5. Linderholm, L.; Biague, A.; Mansson, F.; Norrgren, H.; Bergman, A.; Jakobsson, K. Human exposure to persistent organic pollutants in west Africa-A temporal trend study from guinea-bissau. Environ. Int. 2010, 36, 675-682. [CrossRef] [PubMed]

6. Polder, A.; Thomsen, C.; Lindström, G.; Løken, K.B.; Skaare, J.U. Levels and temporal trends of chlorinated pesticides, polychlorinated biphenyls and brominated flame retardants in individual human breast milk samples from northern and southern norway. Chemosphere 2008, 73, 14-23. [CrossRef] [PubMed]

7. Pumarega, J.; Gasull, M.; Lee, D.H.; Lopez, T.; Porta, M. Number of persistent organic pollutants detected at high concentrations in blood samples of the united states population. PLOS ONE 2016, 11, e0160432. [CrossRef] [PubMed]

8. Maqbool, F.; Mostafalou, S.; Bahadar, H.; Abdollahi, M. Review of endocrine disorders associated with environmental toxicants and possible involved mechanisms. Life Sci. 2016, 145, 265-273. [CrossRef] [PubMed]

9. Kabir, E.R.; Rahman, M.S.; Rahman, I. A review on endocrine disruptors and their possible impacts on human health. Environ. Toxicol. Pharmacol. 2015, 40, 241-258. [CrossRef] [PubMed]

10. Vizcaino, E.; Grimalt, J.O.; Fernandez-Somoano, A.; Tardon, A. Transport of persistent organic pollutants across the human placenta. Environ. Int. 2014, 65, 107-115. [CrossRef] [PubMed]

11. Costa, L.G.; de Laat, R.; Tagliaferri, S.; Pellacani, C. A mechanistic view of polybrominated diphenyl ether (PBDE) developmental neurotoxicity. Toxicol. Lett. 2014, 230, 282-294. [CrossRef] [PubMed]

12. Giordano, G.; Costa, L.G. Developmental neurotoxicity: Some old and new issues. ISRN Toxicol. 2012, 2012, 814795. [CrossRef] [PubMed]

13. Kodavanti, P.R.S. Neurotoxicity of persistent organic pollutants: Possible mode(s) of action and further considerations. Dose Response 2005, 3, 273-305. [CrossRef] [PubMed]

14. Berghuis, S.A.; Bos, A.F.; Sauer, P.J.; Roze, E. Developmental neurotoxicity of persistent organic pollutants: An update on childhood outcome. Arch. Toxicol. 2015, 89, 687-709. [CrossRef] [PubMed]

15. Grandjean, P.; Landrigan, P.J. Developmental neurotoxicity of industrial chemicals. Lancet 2006, 368, 2167-2178. [CrossRef]

16. Rice, D.; Barone, S., Jr. Critical periods of vulnerability for the developing nervous system: Evidence from humans and animal models. Environ. Health Perspect. 2000, 108 (Suppl. 3), 511-533. [CrossRef] [PubMed]

17. Wang, X.; Li, B.; Zhao, W.D.; Liu, Y.J.; Shang, D.S.; Fang, W.G.; Chen, Y.H. Perfluorooctane sulfonate triggers tight junction "opening" in brain endothelial cells via phosphatidylinositol 3-kinase. Biochem. Biophys. Res. Commun. 2011, 410, 258-263. [CrossRef] [PubMed]

18. Chen, J.; Das, S.R.; La Du, J.; Corvi, M.M.; Bai, C.; Chen, Y.; Liu, X.; Zhu, G.; Tanguay, R.L.; Dong, Q.; et al. Chronic PFOS exposures induce life stage-specific behavioral deficits in adult zebrafish and produce malformation and behavioral deficits in F1 offspring. Environ. Toxicol. Chem. 2013, 32, 201-206. [CrossRef]

19. Hallgren, S.; Fredriksson, A.; Viberg, H. More signs of neurotoxicity of surfactants and flame retardants-Neonatal PFOS and PBDE 99 cause transcriptional alterations in cholinergic genes in the mouse CNS. Environ. Toxicol. Pharmacol. 2015, 40, 409-416. [CrossRef] [PubMed] 
20. Huang, H.; Huang, C.; Wang, L.; Ye, X.; Bai, C.; Simonich, M.T.; Tanguay, R.L.; Dong, Q. Toxicity, uptake kinetics and behavior assessment in zebrafish embryos following exposure to perfluorooctanesulphonicacid (PFOS). Aquat. Toxicol. 2010, 98, 139-147. [CrossRef] [PubMed]

21. Lee, H.G.; Lee, Y.J.; Yang, J.H. Perfluorooctane sulfonate induces apoptosis of cerebellar granule cells via a ROS-dependent protein kinase C signaling pathway. Neurotoxicology 2012, 33, 314-320. [CrossRef] [PubMed]

22. Salgado, R.; Lopez-Doval, S.; Pereiro, N.; Lafuente, A. Perfluorooctane sulfonate (PFOS) exposure could modify the dopaminergic system in several limbic brain regions. Toxicol. Lett. 2016, 240, 226-235. [CrossRef] [PubMed]

23. Yang, X.; Wang, L.; Sun, W.; Xue, Z. Effects of perfluorooctane sulfonate on amino acid neurotransmitters and glutamine synthetase in rats. J. Hyg. Res. 2009, 38, 19-21.

24. Shi, X.; Zhou, B. The role of Nrf2 and mapk pathways in PFOS-induced oxidative stress in zebrafish embryos. Toxicol. Sci. 2010, 115, 391-400. [CrossRef] [PubMed]

25. Chen, J.; Wang, X.; Ge, X.; Wang, D.; Wang, T.; Zhang, L.; Tanguay, R.L.; Simonich, M.; Huang, C.; Dong, Q. Chronic perfluorooctanesulphonic acid (PFOS) exposure produces estrogenic effects in zebrafish. Environ. Pollut. 2016, 218, 702-708. [CrossRef] [PubMed]

26. Chen, J.; Tanguay, R.L.; Tal, T.L.; Gai, Z.; Ma, X.; Bai, C.; Tilton, S.C.; Jin, D.; Yang, D.; Huang, C.; et al. Early life perfluorooctanesulphonic acid (PFOS) exposure impairs zebrafish organogenesis. Aquat. Toxicol. 2014, 150, 124-132. [CrossRef] [PubMed]

27. Spulber, S.; Kilian, P.; Wan Ibrahim, W.N.; Onishchenko, N.; Ulhaq, M.; Norrgren, L.; Negri, S.; Di Tuccio, M.; Ceccatelli, S. PFOS induces behavioral alterations, including spontaneous hyperactivity that is corrected by dexamfetamine in zebrafish larvae. PLoS ONE 2014, 9, e94227. [CrossRef] [PubMed]

28. Bailey, J.; Oliveri, A.; Levin, E.D. Zebrafish model systems for developmental neurobehavioral toxicology. Birth Defects Res. Part C Embryo Today Rev. 2013, 99, 14-23. [CrossRef] [PubMed]

29. De Esch, C.; Slieker, R.; Wolterbeek, A.; Woutersen, R.; de Groot, D. Zebrafish as potential model for developmental neurotoxicity testing: A mini review. Neurotoxicol. Teratol. 2012, 34, 545-553. [CrossRef] [PubMed]

30. Linney, E.; Upchurch, L.; Donerly, S. Zebrafish as a neurotoxicological model. Neurotoxicol. Teratol. 2004, 26, 709-718. [CrossRef]

31. Melvin, S.D.; Wilson, S.P. The utility of behavioral studies for aquatic toxicology testing: A meta-analysis. Chemosphere 2013, 93, 2217-2223. [CrossRef] [PubMed]

32. Rihel, J.; Schier, A.F. Behavioral screening for neuroactive drugs in zebrafish. Dev. Neurobiol. 2012, 72, 373-385. [CrossRef] [PubMed]

33. Tierney, K.B. Behavioural assessments of neurotoxic effects and neurodegeneration in zebrafish. Biochim. Biophys. Acta 2011, 1812, 381-389. [CrossRef] [PubMed]

34. Scott, G.R.; Sloman, K.A. The effects of environmental pollutants on complex fish behaviour: Integrating behavioural and physiological indicators of toxicity. Aquat. Toxicol. 2004, 68, 369-392. [CrossRef] [PubMed]

35. Chen, L.; Huang, C.; Hu, C.; Yu, K.; Yang, L.; Zhou, B. Acute exposure to DE-71: Effects on locomotor behavior and developmental neurotoxicity in zebrafish larvae. Environ. Toxicol. Chem. 2012, 31, 2338-2344. [CrossRef] [PubMed]

36. Puttonen, H.; Sundvik, M.; Rozov, S.; Chen, Y.-C.; Panula, P. Acute ethanol treatment upregulates Th1, Th2, and hdc in larval zebrafish in stable networks. Front. Neural Circuits 2013, 7, 102. [CrossRef] [PubMed]

37. Wang, X.; Yang, L.; Wu, Y.; Huang, C.; Wang, Q.; Han, J.; Guo, Y.; Shi, X.; Zhou, B. The developmental neurotoxicity of pbdes: Effect of DE-71 on dopamine in zebrafish larvae. Environ. Toxicol. Chem. 2015, 34, 1119-1126. [CrossRef] [PubMed]

38. Chen, X.; Huang, C.; Wang, X.; Chen, J.; Bai, C.; Chen, Y.; Chen, X.; Dong, Q.; Yang, D. BDE-47 disrupts axonal growth and motor behavior in developing zebrafish. Aquat. Toxicol. 2012, 120-121, 35-44. [CrossRef]

39. National Research Council. Complex Mixtures: Methods for In Vivo Toxicity Testing; National Academies Press: Washington, DC, USA, 1988.

40. Daouk, T.; Larcher, T.; Roupsard, F.; Lyphout, L.; Rigaud, C.; Ledevin, M.; Loizeau, V.; Cousin, X. Long-term food-exposure of zebrafish to PCB mixtures mimicking some environmental situations induces ovary pathology and impairs reproduction ability. Aquat. Toxicol. 2011, 105, 270-278. [CrossRef] [PubMed]

41. Gonçalves, R.; Scholze, M.; Ferreira, A.M.; Martins, M.; Correia, A.D. The joint effect of polycyclic aromatic hydrocarbons on fish behavior. Environ. Res. 2008, 108, 205-213. [CrossRef] [PubMed] 
42. Péan, S.; Daouk, T.; Vignet, C.; Lyphout, L.; Leguay, D.; Loizeau, V.; Bégout, M.-L.; Cousin, X. Long-term dietary-exposure to non-coplanar pcbs induces behavioral disruptions in adult zebrafish and their offspring. Neurotoxicol. Teratol. 2013, 39, 45-56. [CrossRef]

43. Keiter, S.; Baumann, L.; Färber, H.; Holbech, H.; Skutlarek, D.; Engwall, M.; Braunbeck, T. Long-term effects of a binary mixture of perfluorooctane sulfonate (PFOS) and bisphenol a (BPA) in zebrafish (Danio rerio). Aquat. Toxicol. 2012, 118-119, 116-129. [CrossRef] [PubMed]

44. Du, J.; Wang, S.; You, H.; Liu, Z. Effects of zno nanoparticles on perfluorooctane sulfonate induced thyroid-disrupting on zebrafish larvae. J. Environ. Sci. 2016, 47, 153-164. [CrossRef]

45. Wilson, J.; Berntsen, H.F.; Zimmer, K.E.; Frizzell, C.; Verhaegen, S.; Ropstad, E.; Connolly, L. Effects of defined mixtures of persistent organic pollutants (POPs) on multiple cellular responses in the human hepatocarcinoma cell line, HepG2, using high content analysis screening. Toxicol. Appl. Pharmacol. 2016, 294, 21-31. [CrossRef] [PubMed]

46. Wilson, J.; Berntsen, H.F.; Zimmer, K.E.; Verhaegen, S.; Frizzell, C.; Ropstad, E.; Connolly, L. Do persistent organic pollutants interact with the stress response? Individual compounds, and their mixtures, interaction with the glucocorticoid receptor. Toxicol. Lett. 2016, 241, 121-132. [CrossRef] [PubMed]

47. Groten, J.P.; Feron, V.J.; Sühnel, J. Toxicology of simple and complex mixtures. Trends Pharmacol. Sci. 2001, 22, 316-322. [CrossRef]

48. Onishchenko, N.; Fischer, C.; Wan Ibrahim, W.N.; Negri, S.; Spulber, S.; Cottica, D.; Ceccatelli, S. Prenatal exposure to PFOS or PFOA alters motor function in mice in a sex-related manner. Neurotoxic. Res. 2011, 19, 452-461. [CrossRef] [PubMed]

49. Fuentes, S.; Colomina, M.T.; Vicens, P.; Domingo, J.L. Influence of maternal restraint stress on the long-lasting effects induced by prenatal exposure to perfluorooctane sulfonate (PFOS) in mice. Toxicol. Lett. 2007, 171, 162-170. [CrossRef] [PubMed]

50. Hagenaars, A.; Stinckens, E.; Vergauwen, L.; Bervoets, L.; Knapen, D. Pfos affects posterior swim bladder chamber inflation and swimming performance of zebrafish larvae. Aquat. Toxicol. 2014, 157, 225-235. [CrossRef] [PubMed]

51. Thomas, F.; Abdolrahman, K.; Juan, G.H.J.; Anna, M.L.-S.; Theodore, H.; Erik, R. Toxin induced behavioural aberrations in larval zebrafish are dependent on minor methodological alterations: The importance of standardisation. Toxicol. Lett. submitted for publication. 2016.

52. Guo, S. Using zebrafish to assess the impact of drugs on neural development and function. Expert Opin. Drug Discov. 2009, 4, 715-726. [CrossRef] [PubMed]

53. Nishimura, Y.; Murakami, S.; Ashikawa, Y.; Sasagawa, S.; Umemoto, N.; Shimada, Y.; Tanaka, T. Zebrafish as a systems toxicology model for developmental neurotoxicity testing. Congenit. Anom. 2014, 55, 1-16. [CrossRef]

54. Staal, Y.C.M.; Pushparajah, D.S.; van Herwijnen, M.H.M.; Gottschalk, R.W.H.; Maas, L.M.; Ioannides, C.; van Schooten, F.J.; van Delft, J.H.M. Interactions between polycyclic aromatic hydrocarbons in binary mixtures: Effects on gene expression and DNA adduct formation in precision-cut rat liver slices. Mutagenesis 2008, 23, 491-499. [CrossRef] [PubMed]

55. Lopez-Doval, S.; Salgado, R.; Fernandez-Perez, B.; Lafuente, A. Possible role of serotonin and neuropeptide Y on the disruption of the reproductive axis activity by perfluorooctane sulfonate. Toxicol. Lett. 2015, 233, 138-147. [CrossRef]

56. Shi, X.; Liu, C.; Wu, G.; Zhou, B. Waterborne exposure to PFOS causes disruption of the hypothalamuspituitary-thyroid axis in zebrafish larvae. Chemosphere 2009, 77, 1010-1018. [CrossRef] [PubMed]

57. Kudryavtseva, N.N. Serotonergic control of aggressive behavior: Novel approaches-New interpretations. Zhurnal Vysshei Nervnoi Deiatelnosti Imeni I P Pavlova 2015, 65, 546-563. [PubMed]

58. Tritsch, N.X.; Granger, A.J.; Sabatini, B.L. Mechanisms and functions of gaba co-release. Nat. Rev. Neurosci. 2016, 17, 139-145. [CrossRef] [PubMed]

59. Chen, Y.C.; Sundvik, M.; Rozov, S.; Priyadarshini, M.; Panula, P. MANF regulates dopaminergic neuron development in larval zebrafish. Dev. Biol. 2012, 370, 237-249. [CrossRef] [PubMed]

60. Zhao, H.; Liu, Y.; Cheng, L.; Liu, B.; Zhang, W.; Guo, Y.J.; Nie, L. Mesencephalic astrocyte-derived neurotrophic factor inhibits oxygen-glucose deprivation-induced cell damage and inflammation by suppressing endoplasmic reticulum stress in rat primary astrocytes. J. Mol. Neurosci. 2013, 51, 671-678. [CrossRef] [PubMed] 
61. De Groef, B.; van der Geyten, S.; Darras, V.M.; Kuhn, E.R. Role of corticotropin-releasing hormone as a thyrotropin-releasing factor in non-mammalian vertebrates. Gen. Comp. Endocrinol. 2006, 146, 62-68. [CrossRef] [PubMed]

62. Ohsawa, Y.; Hirasawa, N. The role of histamine H1 and H4 receptors in atopic dermatitis: From basic research to clinical study. Allergol. Int. 2014, 63, 533-542. [CrossRef] [PubMed]

63. Noyes, P.D.; Haggard, D.E.; Gonnerman, G.D.; Tanguay, R.L. Advanced morphological—Behavioral test platform reveals neurodevelopmental defects in embryonic zebrafish exposed to comprehensive suite of halogenated and organophosphate flame retardants. Toxicol. Sci. 2015, 145, 177-195. [CrossRef] [PubMed]

64. Zhao, J.; Xu, T.; Yin, D.Q. Locomotor activity changes on zebrafish larvae with different 2,2', 4,4'-tetrabromodiphenyl ether (PBDE-47) embryonic exposure modes. Chemosphere 2014, 94, 53-61. [CrossRef] [PubMed]

65. Peng, X.; Lin, J.; Zhu, Y.; Liu, X.; Zhang, Y.; Ji, Y.; Yang, X.; Zhang, Y.; Guo, N.; Li, Q. Anxiety-related behavioral responses of pentylenetetrazole-treated zebrafish larvae to light-dark transitions. Pharmacol. Biochem. Behav. 2016, 145, 55-65. [CrossRef] [PubMed]

66. Smith, D. Worldwide trends in DDT levels in human breast milk. Int. J. Epidemiol. 1999, 28, $179-188$. [CrossRef] [PubMed]

67. Berntsen, H.F.; Vidar, B.; Cathrine, T.; Erik, R.; Karin, E.Z. The synthesis of an environmentally relevant mixture of persistent organic pollutants for use in in vivo and in vitro studies. Toxicol. Lett. submitted for publication. 2016.

68. Padilla, S.; Hunter, D.L.; Padnos, B.; Frady, S.; MacPhail, R.C. Assessing locomotor activity in larval zebrafish: Influence of extrinsic and intrinsic variables. Neurotoxicol. Teratol. 2011, 33, 624-630. [CrossRef] [PubMed]

69. Bytingsvik, J.; van Leeuwen, S.P.; Hamers, T.; Swart, K.; Aars, J.; Lie, E.; Nilsen, E.M.; Wiig, O.; Derocher, A.E.; Jenssen, B.M. Perfluoroalkyl substances in polar bear mother-cub pairs: A comparative study based on plasma levels from 1998 and 2008. Environ. Int. 2012, 49, 92-99. [CrossRef] [PubMed]

70. Jana, W.; Jacob, D.B.; Urs, B.; Derek, M.; Ting, R.; Alejiandra, T.; Foppe, S.; Branislav, V.; Fabrica, C.; Heidelore, F. PFAS Analysis in Water for the Global Monitoring Plan of the Stockholm Convention; United Nations Environment Programme (UNEP): Geneva, Switzerland, 2015.

71. Polder, A.; Muller, M.B.; Lyche, J.L.; Mdegela, R.H.; Nonga, H.E.; Mabiki, F.P.; Mbise, T.J.; Skaare, J.U.; Sandvik, M.; Skjerve, E.; et al. Levels and patterns of persistent organic pollutants (POPs) in tilapia (Oreochromis sp.) from four different lakes in Tanzania: Geographical differences and implications for human health. Sci. Total Environ. 2014, 488-489, 252-260. [CrossRef] [PubMed]

72. Vandesompele, J.; De Preter, K.; Pattyn, F.; Poppe, B.; Van Roy, N.; De Paepe, A.; Speleman, F. Accurate normalization of real-time quantitative RT-PCR data by geometric averaging of multiple internal control genes. Genome Biol. 2002, 3. [CrossRef] 